\title{
BMJ open Right ventricular ejection fraction during exercise as a predictor of mortality in patients awaiting lung transplantation: a cohort study
}

\author{
Nedim Selimovic, ${ }^{1}$ Bert Andersson, ${ }^{1}$ Odd Bech-Hanssen, ${ }^{2}$ Milan Lomsky, ${ }^{2}$ \\ Gerdt C Riise, ${ }^{3}$ Bengt Rundqvist ${ }^{1}$
}

To cite: Selimovic N, Andersson B, BechHanssen 0, et al. Right ventricular ejection fraction during exercise as a predictor of mortality in patients awaiting lung transplantation: a cohort study. BMJ Open 2013;3:e002108

doi:10.1136/bmjopen-2012002108

- Prepublication history for this paper are available online. To view these files please visit the journal online (http://dx.doi.org/10.1136/ bmjopen-2012-002108).

Received 16 October 2012 Revised 25 February 2012 Accepted 26 February 2012

This final article is available for use under the terms of the Creative Commons Attribution Non-Commercial 2.0 Licence; see http://bmjopen.bmj.com

\footnotetext{
${ }^{1}$ Department of Cardiology, Sahlgrenska University Hospital, Gothenburg, Sweden

${ }^{2}$ Department of Clinical Physiology, Sahlgrenska University Hospital, Gothenburg, Sweden ${ }^{3}$ Sahlgrenska Transplantation Centre, Sahlgrenska University Hospital, Gothenburg, Sweden
}

Correspondence to Dr Nedim Selimovic; nedim.selimovic@vgregion.se

\section{ABSTRACT}

Objective: The occurrence of right ventricular dysfunction is a well-known indicator of poor prognosis in patients with chronic cardiopulmonary disease. The role of right ventricular ejection fraction (RVEF) at rest and during exercise as predictors of outcome in patients awaiting lung transplantation (LTX) is unclear.

Design: We performed a retrospective analysis of lung transplant candidates who had undergone equilibrium radionuclide angiography (ERNA), to determine baseline and exercise RVEF. Lung function, gas exchange and pulmonary haemodynamics were also assessed.

Patients and main outcome measures: 152 patients (mean age $47 \pm 11$ years; $59 \%$ women) were included in the study. Primary endpoint was death on the waiting list for LTx. Main diagnoses were $\alpha-1$ antitrypsin deficiency $(n=35)$, chronic obstructive pulmonary disease $(n=41)$, cystic fibrosis $(n=10)$, interstitial lung disease $(n=34)$ and pulmonary arterial hypertension $(\mathrm{n}=32)$. Twenty-five patients died (16, $4 \%)$. LTX was performed in 121 patients. The mean RVEF at rest was equal to mean RVEF during exercise $(38 \pm 12 \%)$. In univariate analysis RVEF at rest, RVEF during exercise, heart rate and forced volume capacity (FVC) \% of predicted were factors significantly associated with risk of death. In multivariate analysis RVEF during exercise and FVC\% of predicted were independent predictors of death.

Conclusions: In lung transplant candidates, right ventricular function during exercise is a stronger predictor of outcome than right ventricular function at rest. RVEF during exercise assessed by ERNA could be incorporated into priority-based allocation algorithms for LTX.

\section{INTRODUCTION}

Right ventricular (RV) dysfunction is a wellknown marker of poor prognosis in patients with different cardiopulmonary diseases. RV failure is associated with adverse outcome in

\section{ARTICLE SUMMARY}

\section{Article focus}

- The purpose of this study was to explore the influence of right ventricular (RV) function at rest and during exercise, measured by equilibrium radionuclide angiography (ERNA) on mortality in patients awaiting lung transplantation (LTX).

\section{Key messages}

- The right ventricular ejection fraction (RVEF) during exercise is a stronger predictor of negative outcome than RVEF at rest in lung transplant candidates.

- The inability to augment RVEF during exercise is a sign of latent dysfunction not evident at rest, and a sign of subnormal RV exercise reserve.

Strengths and limitations of this study

- We have shown for the first time that RVEF during exercise, measured by ERNA, plays a more important role for survival than RVEF at rest in lung transplant candidates.

- Patients with low RVEF during exercise should be given higher priority in organ allocation.

- Non-invasive assessment of right heart function during exercise is still a challenge, and ERNA could be used for assessment of RVEF with reasonable accuracy.

- The limitations of this study were the retrospective analysis of the patients accepted for LTx at a single centre, and a mixture of different diagnosis.

patients with left heart failure $^{1-4}$ and in patients with pulmonary arterial hypertension $(\mathrm{PAH}) .^{5-7}$ Kawut et $a l^{8}$ showed that a lower right ventricular ejection fraction (RVEF) of 5\% at baseline in patients with $\mathrm{PAH}$ confers a more than $60 \%$ increase in the risk for death.

LTx is currently a therapeutic option for carefully selected patients with advanced lung disease ${ }^{9-10}$ Patients listed for LTx face a long waiting time, and mortality on the 
waiting list is still high. ${ }^{11-13}$ The association between RV function and outcome in patients with end-stage lung disease who are accepted for LTx is not known.

Non-invasive assessment of RV function at rest and during exercise is still a challenge. Despite the limitations of EF as a means of assessing RV function, it remains a popular technique due to conceptual simplicity and the availability of multiple modalities that can provide complementary information. RVEF provides an integrated view of the interaction of RV contraction and RV load. MRI is considered the golden-standard for measurement of the $\mathrm{RVEF}^{14}$ but this investigation is accompanied by some drawbacks and is still not available for assessment of RV function during exercise. Equilibrium radionuclide angiography (ERNA) can be used for assessment of RV function with reasonable accuracy. ${ }^{15}{ }^{16}$ It has been used for serial assessment of RVEF at rest and during exercise, and in heart failure populations it has been shown to be a predictor of outcome. ${ }^{1}$ Assessment of RV function at rest and during exercise by ERNA has been part of the routine pretransplant investigation of all potential lung transplant candidates at our institution.

We hypothesised that RVEF during exercise would better reflect the status of RV than RVEF at rest. We also hypothesised that lower RVEF during exercise might be associated with an increased risk for death in patients awaiting LTx.

\section{MATERIAL AND METHODS}

We performed a retrospective study of 282 adult patients with advanced lung disease who were accepted for LTx at Sahlgrenska University Hospital between January 1990 and December 2003. Since 2001, evaluation of the RV function has been performed by echocardiography and this was the reason that only $72 \%$ of all patients accepted for LTx underwent ERNA at rest and 54\% underwent ERNA during exercise. In the final analysis, we included only patients who had undergone ERNA investigation during exercise. The study was approved by Institutional Review Board of University of Gothenburg (approval number (Dnr): 341-06).

All patients who were evaluated for LTx routinely underwent laboratory testing, pulmonary function testing, transthoracic echocardiography, coronary angiography, ERNA and right heart catheterisation. Primary outcome was a death in a patient on the waiting list.

Follow-up was complete and outcome had been determined for all patients by the end of the study (31 December 2003).

\section{Equilibrium radionuclide angiography}

ERNA was performed at rest and during submaximal and maximal exercise in the supine position. The patient's red blood cells were labelled with $925 \mathrm{MBq}$ Tc-99m pertechnetate using an in vivo/in vitro technique. Acquisition was conducted using a single-crystal $y$ camera with a general all-purpose collimator placed with a $20^{\circ}$ caudal tilt in left anterior oblique position to give the best separation of the right and left ventricles. ${ }^{15}$ The images were obtained in frame mode. Time/frame was $50 \mathrm{~ms}$ at a heart rate of $<90 / \mathrm{min}$ and $40 \mathrm{~ms}$ at a heart rate of $>90 / \mathrm{min}$. Acquisition at rest was stopped when the mean left ventricular count density was approximately 130/pixel (matrix size: 64×64; regular field of view camera, zoom 1.3).

The exercise was performed using a bicycle ergometer with the patient supine. Exercise was started at a workload of $25 \mathrm{~W}$ with an increment of $25 \mathrm{~W}$ every 4 min. Equilibrium radionuclide angiographic acquisition was conducted during the last $3 \mathrm{~min}$ of each stage. The 12-lead ECG was monitored throughout the examination. The criteria for terminating exercise were severe angina pectoris, severe fatigue, shortness of breath, a decrease in systolic blood pressure, complex ventricular arrhythmias or marked ST-segment changes. RVEF was calculated using manually drawn RV regions of interest and background region of interest. ${ }^{15} 17$

\section{Other measurements}

Dynamic spirometric tests were carried out using a Bernstein spirometer (Vitalograph, Burkingham, UK) until 1994, and then on an air rolling-seal spirometer (Sensormedicus, California, USA) according to standard criteria of the American Thoracic Society. ${ }^{18}$ Arterial blood gases, $\mathrm{PaO}_{2}$ and $\mathrm{PaCO}_{2}$ were obtained with patients in the upright position and breathing room air.

Right heart catheterisation was performed at rest using the internal jugular vein approach, with a Swan-Ganz pulmonary artery catheter (Baxter Health Care Corp., Edwards Div., Santa Ana, California, USA).

$\mathrm{RV}$, pulmonary artery and pulmonary capillary wedge pressures were measured. Cardiac output was determined by the thermodilution method. Cardiac index was calculated from cardiac output divided by the body surface area. Pulmonary vascular resistance (PVR) was calculated from the ratio of the transpulmonary gradient (mean pulmonary pressure minus the mean pulmonary capillary wedge pressure) and cardiac output.

\section{Statistical analysis}

Continuous variables are presented as mean $\pm \mathrm{SD}$ or median (IQR). Categorical variables are summarised as frequency and percentage. SPSS software version 17.0.1 (SPSS; Chicago, Illinois, USA) was used for all analyses. Comparisons between groups were performed by independent-samples Student's t test, Mann-Whitney U-test or $\chi^{2}$ test where appropriate. Paired t test was used to compare two sets of quantitative data when data in each sample set were related in a special way.

Potential risk factors were initially analysed for significant association with mortality on the waiting list using Cox proportional hazards model for continuous variables.

Risk factors with a level of significance of $\mathrm{p}<0.05$ in the univariate analysis were included in the multivariate 
Table 1 Outcome of patients listed for LTx between 1990 and 2003 who underwent equilibrium radionuclide angiography during exercise

\begin{tabular}{lccl}
\hline Diagnosis & $\begin{array}{c}\text { Accepted } \\
\text { for LTx }(\mathbf{n})\end{array}$ & $\begin{array}{l}\text { Transplanted } \\
(\mathbf{n})\end{array}$ & $\begin{array}{l}\text { Mortality on } \\
\text { the waiting } \\
\text { list }(\mathbf{n})\end{array}$ \\
\hline$\alpha-1$ ATD & 35 & 33 & 2 \\
COPD & 41 & 34 & 6 \\
CF & 10 & 7 & 2 \\
ILD & 34 & 26 & 8 \\
PAH & 32 & 21 & 7 \\
Total & 152 & 121 & 25 \\
\hline
\end{tabular}

$\alpha-1$ ATD, $\alpha-1$ antitrypsin deficiency; CF, cystic fibrosis; COPD, chronic obstructive pulmonary disease; ILD, interstitial lung disease; LTx, lung transplantation; PAH, pulmonary arterial hypertension.

model. We chose $\mathrm{p}<0.05$ as the inclusion criterion for multivariate Cox regression analysis because of the small number of events $(n=25)$.

Kaplan-Meier graphs were used in the survival analysis and the log-rank test was used to test differences between curves. Patients who underwent LTx were discontinued from the study at the time of transplantation, and patients who were alive and still waiting for transplantation on the date when the study closed were also censored.

\section{RESULTS}

In the final analysis, we included 152 patients who had undergone ERNA during exercise. The mean age was $47 \pm 11$ (SD) years and 59\% were women. Twenty-five patients on the waiting list had died (the non survivor group, $16.4 \%)$. One hundred and twenty-one patients underwent LTx, and six patients were alive and still waiting for LTx at the end of the study (the survivor group, $\mathrm{n}=127 ; 83.6 \%$; table 1 ). Patients on the waiting list with $\alpha-1$ antutrypsin deficiency $(\alpha-1$ ATD) had the lowest mortality and those with interstitial lung disease (ILD) had the highest mortality. The median waiting time for transplanted patients during the study period was 299 (136-619) days and median time to death for patients on the waiting list was 188 (44-559) days.

\section{Comparison between survivors and non-survivors on the waiting list}

Table 2 shows the patient characteristics, haemodynamics, dynamic spirometric indices, gas exchange, RVEF and left ventricular ejection fraction (LVEF) at rest and during exercise at time of referral for transplantation. Patients on the waiting list who died had a significantly lower RVEF at rest $(32 \pm 14 \%$ vs $39 \pm 11 \%, \mathrm{p}=0.01)$ and even more significantly lower RVEF during exercise $(30 \pm 13 \%$ vs $39 \pm 12 \%, \mathrm{p}=0.001)$. Seventy-two per cent of non-survivors had unchanged or reduced RVEF during exercise as compared with $57 \%$ of survivors $(p=0.19)$.

Table 2 Patient characteristics, spirometric indices, gas exchange, haemodynamics and ERNA data at the time of referral to transplantation

\begin{tabular}{|c|c|c|c|c|c|}
\hline \multicolumn{3}{|l|}{ Non-survivors } & \multicolumn{3}{|l|}{ Survivors } \\
\hline Variable & Value & $\mathbf{N}$ & $\overline{\text { Value }}$ & $\mathbf{N}$ & p Value \\
\hline Age, year & $45 \pm 12$ & 25 & $47 \pm 11$ & 127 & 0.22 \\
\hline Sex, female; no. (\%) & $14(56)$ & 25 & $75(59)$ & 127 & 0.82 \\
\hline BMI & $20.3 \pm 4.5$ & 24 & $21.9 \pm 4.4$ & 127 & 0.09 \\
\hline \multicolumn{6}{|l|}{ Dynamic spirometric tests } \\
\hline FVC \%, predicted & $52 \pm 21$ & 25 & $59 \pm 21$ & 126 & 0.01 \\
\hline FEV1\%, predicted & $39 \pm 23$ & 25 & $38 \pm 29$ & 126 & 0.83 \\
\hline \multicolumn{6}{|l|}{ Gas exchange } \\
\hline $\mathrm{P}_{\mathrm{a}} \mathrm{O}_{2}, \mathrm{kPa}$ & $7.7 \pm 1.4$ & 23 & $8.2 \pm 2$ & 122 & 0.23 \\
\hline $\mathrm{P}_{\mathrm{a}} \mathrm{CO}_{2}, \mathrm{kPa}$ & $5.7 \pm 1.7$ & 23 & $5.5 \pm 1.2$ & 122 & 0.6 \\
\hline \multicolumn{6}{|l|}{ Haemodynamics } \\
\hline Heart rate & $94 \pm 12$ & 22 & $88 \pm 14$ & 120 & 0.06 \\
\hline Ram, mm Hg & $3 \pm 6$ & 23 & $3 \pm 3$ & 120 & 0.56 \\
\hline Pam, $\mathrm{mm} \mathrm{Hg}$ & $37 \pm 26$ & 24 & $30 \pm 17$ & 121 & 0.1 \\
\hline $\mathrm{CO}, \mathrm{l} / \mathrm{min}$ & $4.9 \pm 1.1$ & 20 & $4.9 \pm 1.3$ & 119 & 0.89 \\
\hline PVR, wood units & $5.7 \pm 5.1$ & 20 & $4.8 \pm 4.4$ & 117 & 0.44 \\
\hline RVEF at rest (\%) & $32 \pm 14$ & 25 & $39 \pm 11$ & 127 & 0.01 \\
\hline RVEF on exercise (\%) & $30 \pm 13$ & 25 & $39 \pm 12$ & 127 & 0.001 \\
\hline LVEF at rest (\%) & $62 \pm 12$ & 25 & $65 \pm 10$ & 127 & 0,12 \\
\hline LVEF on exercise (\%) & $65 \pm 12$ & 25 & $70 \pm 10$ & 127 & 0.054 \\
\hline Median waiting time, in days (IQR) & $188(44-559)$ & 25 & $307(138-662)$ & 127 & 0.2 \\
\hline
\end{tabular}

All values, except sex are mean \pm SD.

BMI, body mass index; $\mathrm{CO}$, cardiac output; $\mathrm{FEV}_{\mathbf{1}} \%$, forced expiratory volume \%; FVC \%, forced vital capacity \%; HR, heart rate; Ram, right atrial mean pressure; LVEF, left ventricular ejection fraction; Pam, pulmonary artery mean pressure; $\mathrm{P}_{\mathrm{a}} \mathrm{O}_{2}$, arterial oxygen partial pressure; $\mathrm{P}_{\mathrm{a}} \mathrm{CO}_{2}$, arterial carbon dioxide partial pressure; PVR, pulmonary vascular resistance; RVEF, right ventricular ejection fraction (radionuclide ventriculogram) 
Table 3 Right and left ventricular ejection fraction at rest and during exercise in patients with different diagnoses

\begin{tabular}{|c|c|c|c|c|c|c|}
\hline & RVEF \% rest & RVEF \% exercise & p Value & LVEF \% at rest & LVEF \% on exercise & p Value \\
\hline COPD, $n=41$ & $41 \pm 10$ & $43 \pm 10$ & 0.08 & $66 \pm 11$ & $70 \pm 11$ & 0.003 \\
\hline$\alpha-1$ ATD, $n=35$ & $39 \pm 9$ & $40 \pm 9$ & 0.35 & $66 \pm 8$ & $70 \pm 8$ & 0.006 \\
\hline ILD, $n=34$ & $38 \pm 10$ & $35 \pm 12$ & 0.05 & $64 \pm 10$ & $69 \pm 10$ & $<0.001$ \\
\hline $\mathrm{PAH}, \mathrm{n}=32$ & $32 \pm 17$ & $31 \pm 15$ & 0.2 & $62 \pm 12$ & $66 \pm 13$ & 0.007 \\
\hline CF, $n=10$ & $38 \pm 8$ & $35 \pm 7$ & 0.036 & $69 \pm 10$ & $72 \pm 9$ & 0.07 \\
\hline
\end{tabular}

The non-survivors had lower forced vital capacity (FVC) $\%$ of predicted $(\mathrm{p}=0.01)$, higher heart rate $(\mathrm{p}=0.06)$ and lower $\operatorname{LVEF}(\mathrm{p}=0.054)$ during exercise. There was no significant difference in forced expiratory volume in $1 \mathrm{~s}$ (FEV1) between groups $(\mathrm{p}=0.83)$. There was no significant difference in 6-min walking distance or arterial saturation at rest between the two groups. The non-survivors had more severe arterial desaturation during exercise than the survivors. The results of right heart catheterisation did not show any significant differences.

The mean RVEF at rest and the mean RVEF during exercise for the entire cohort were the same $(38 \pm 12 \%$, $\mathrm{p}=0.87)$. The mean LVEF during exercise for the entire cohort was significantly higher than the LVEF at rest (69 \pm 10 vs $65 \pm 10, \mathrm{p}<0.001)$. Sixty-one per cent of patients managed to cope with a starting load of $25 \mathrm{~W}$ (low capacity) and only $14 \%$ managed to get up the third and fourth levels ( 75 and $100 \mathrm{~W}$ high capacity). There was no significant difference in survival between the two groups (low and high physical capacities, $\mathrm{p}=0.89$ ).

Patients with PAH, ILD and cystic fibrosis (CF) showed reduced RVEF during exercise in comparison to the value at rest (table 3 ).

\section{Univariate and multivariate analysis}

By univariate analysis, RVEF at rest, RVEF during exercise, HR and FVC\% of predicted were associated with significant risk of death (table 4). Six-minute walking test (6MWT) and New York Heart Association class were excluded from univariate analysis. The reason for excluding the 6MWT from the analysis was the use of the 12 min walking test in the early 1990s. All patients accepted for LTx were in an advanced functional class (IIIB or IV). The lack of increase in RVEF during exercise was not significantly associated with outcome in univariate analysis $(\mathrm{p}=0.16)$.

In multivariate analysis, FVC\% of predicted and RVEF during exercise were found to be independent predictors of mortality (table 5). Patients on the waiting list with RVEF during exercise of $<38 \%$ (the mean value for all 152 patients) had significantly higher mortality (figure 1).

\section{DISCUSSION}

We have shown that RV function estimated by ERNA during exercise is a stronger predictor of mortality in patients with end-stage lung diseases on the waiting list for LTx than RV function at rest.

Table 4 Univariate analysis of possible predictors of mortality in patients on the waiting list

\begin{tabular}{|c|c|c|c|}
\hline Variable & HR & $95 \% \mathrm{Cl}$ & p Value \\
\hline Age & 0.98 & 0.95 to 1.02 & 0.33 \\
\hline LVEF at rest & 0.98 & 0.94 to 1.01 & 0.22 \\
\hline LVEF on exercise & 0.98 & 0.95 to 1.02 & 0.27 \\
\hline RVEF at rest & 0.97 & 0.94 to 0.99 & 0.04 \\
\hline RVEF on exercise & 0.96 & 0.94 to 0.99 & 0.009 \\
\hline HR & 1.04 & 1.001 to 1.07 & 0.04 \\
\hline Ram & 0.92 & 0.79 to 1.05 & 0.21 \\
\hline Pam & 1.01 & 0.99 to 1.03 & 0.44 \\
\hline $\mathrm{CO}$ & 1.08 & 0.76 to 1.55 & 0.67 \\
\hline PVR & 0.98 & 0.89 to 1.08 & 0.72 \\
\hline $\mathrm{P}_{\mathrm{a}} \mathrm{O}_{2}$ & 0.91 & 0.71 to 1.17 & 0.47 \\
\hline $\mathrm{P}_{\mathrm{a}} \mathrm{CO}_{2}$ & 1.16 & 0.85 to 1.58 & 0.35 \\
\hline $\mathrm{FEV}_{\mathbf{1}}$, predicted & 0.99 & 0.98 to 1.01 & 0.38 \\
\hline FVC\%, predicted & 0.97 & 0.95 to 0.99 & 0.02 \\
\hline Desaturation during walking test & 0.97 & 0.95 to 1.001 & 0.06 \\
\hline
\end{tabular}


Table 5 Multivariate analysis of predictors of mortality in patients on the waiting list

\begin{tabular}{llll}
\hline Variable & HR & 95\% Cl & p Value \\
\hline HR & 1.02 & 0.98 to 1.05 & 0.45 \\
RVEF at rest & 1.03 & 0.97 to 1.09 & 0.35 \\
RVEF on exercise & 0.94 & 0.88 to 0.99 & 0.02 \\
FVC\%, predicted & 0.97 & 0.94 to 0.99 & 0.01 \\
\hline FVC \%, forced vital capacity \%; HR, heart rate; RVEF, right \\
ventricular ejection fraction.
\end{tabular}

The normal exercise RV reserve is defined as an absolute increment in RVEF of at least $5 \% .{ }^{19-21}$ In contrast to normal subjects, many patients with advanced lung disease are able to increase RVEF during exercise, and this may explain the reduced exercise capacity seen in these patients. $^{22} \mathrm{RV}$ dysfunction in patients with pulmonary disease may not be present in the resting state, but may become manifest only under physiological stress such as exercise. ${ }^{23}$ This lack of increase in RVEF during exercise is a sign of latent dysfunction that is not evident at rest, and a sign of subnormal RV exercise reserve.

There are several possible mechanisms behind reduced RV reserve in patients with lung disease.

We know that in patients with pulmonary diseases, the ability to enhance RV systolic performance during exercise is largely determined by the increase in pulmonary resistance and therefore RV afterload. ${ }^{24-26}$ The RV hypertrophy observed in patients with pulmonary hypertension is a compensatory mechanism aimed at reducing the wall tension and thereby oxygen consumption. We know that $\mathrm{RV}$ hypertrophy is relatively common in patients with advanced pulmonary diseases and compensated pulmonary hypertension. It is conceivable that during exercise, oxygen requirements of the hypertrophied RV may

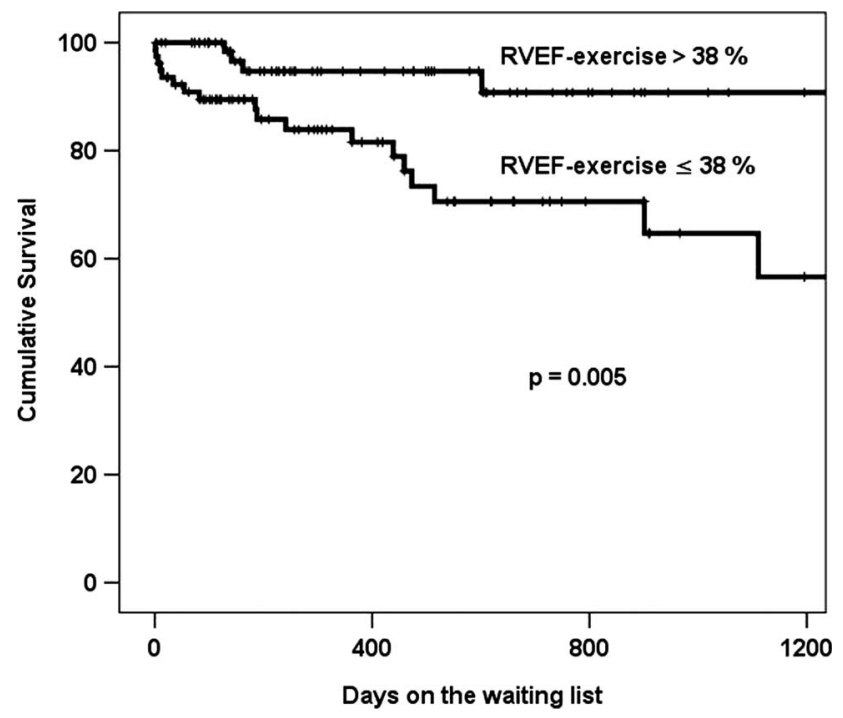

Figure 1 Probability of survival of patients on the waiting list with advanced lung diseases stratified by the mean value of right ventricular ejection fraction during exercise. exceed demand, resulting in relative ischaemia and systolic dysfunction. ${ }^{27}$ Pressure overload of the RV may also lead to RV ischaemia, which may aggravate ventricular dysfunction. $^{28}$ Abnormalities in perfusion of hypertrophied RV may contribute to lower RVEF. ${ }^{29-30}$

Resting arterial hypoxaemia and the severity of ventilatory impairment are important determinants of abnormal exercise RV reserve in patients awaiting LTx. The common factor behind modulated RV exercise performance appears to be altered RV afterload. A restricted, relatively non-recruitable pulmonary vascular bed with inordinately high-pulmonary arterial pressure was considered to be the most likely mechanism for the failure of RVEF to increase normally with exercise. ${ }^{20}$ Olvey $e t a l^{11}$ showed that low-flow oxygen therapy can improve the RVEF response to exercise in some patients with chronic obstructive pulmonary disease (COPD), although maximum exercise performance did not improve.

Another potential cause could be lower arterial oxygen saturation during exercise. In our cohort, arterial saturation during the walking test were significantly lower in patients on the waiting list who subsequently died $(76 \pm 15 \%$ in those who died vs $81 \pm 9 \%$ in those who did not; $\mathrm{p}=0.039$ ). This is similar to the findings of others. ${ }^{32} 33$ The potential mechanism of desaturation in patients with advanced lung disease includes ventilation-perfusion mismatching, intrapulmonary shunts, low mixed venous oxygen saturation and patent foramen ovale.

We cannot exclude myocardial fibrosis as a contributing factor to reduced RV function during exercise. McCann et $a l^{34}$ have demonstrated that fibrosis occurs frequently in patients with pulmonary hypertension and is inversely related to measures of RV systolic function.

The present study has even shown a significant but not strong correlation between RVEF and pulmonary haemodynamics (pulmonary artery pressures, PVR, stroke volume index), LVEF and renal function. Lower LVEF (probably, due to ventricular interdependence), higher PVR and reduced renal function were independently associated with lower RVEF (unpublished data).

Functional assessment of patients with advanced lung disease who are awaiting LTx offers the promise of improved risk stratification beyond that provided by conventional measures of lung disease. We have already accepted 6MWT as a predictor of prognosis in patients with COPD and PAH. Kawut $e t a l^{32}$ showed that CPET was associated with the risk of death in patients with diffuse parenchymal lung disease.

The study had several limitations. It was a retrospective analysis of the patients with advanced lung diseases who were accepted for transplantation at a single centre. Patients who were not accepted and patients who did not undergo ERNA during exercise were excluded from analysis, which may have led to selection bias. Another limitation could have been the mixture of different diagnoses (diseases of the air way (COPD, $\alpha 1$ ATD), diffuse parenchymal/ILD, a pure vascular disease such as PAH and multiple-organ disease-CF). At the same time, this 
combined population strengthened the importance of RV function in survival awaiting LTx. Further limitations were the small study population and the absence of measurement of pulmonary arterial pressure during exercise.

In summary, we have shown for first time that RV function during exercise measured by ERNA plays a more important role for survival of lung transplant candidates on the waiting list than RV function at rest. Assessment of RV function during exercise and discovery of latent RV dysfunction should be subjects of further study.

These results may have implications for prioritisation of patients listed for transplantation regarding organ allocation.

Contributors NS had full access to all data and took responsibility for the integrity of the data and the accuracy of the analyses, contributed to study design, data acquisition, analysis and preparation of the manuscript. BA contributed to the study design, analysis and preparation of the manuscript. $\mathrm{OB}-\mathrm{H}$ contributed with several valuable points and revision of the manuscript. $M L$ contributed with several valuable points, especially regarding ERNA data, and revision of the manuscript. GCR contributed with several valuable points and revision of the manuscript. BR contributed to the conception and design of the study and to preparation of the manuscript. All authors read and approved the final manuscript.

Funding The study was supported by the Swedish Research Council.

Competing interests None.

Ethics approval Institutional Review Board at University of Gothenburg.

Provenance and peer review Not commissioned; externally peer reviewed.

Data sharing statement No additional data are available.

\section{REFERENCES}

1. de Groote P, Millaire A, Foucher-Hossein C, et al. Right ventricular ejection fraction is an independent predictor of survival in patients with moderate heart failure. J Am Coll Cardiol 1998;32:948-54.

2. Di Salvo TG, Mathier M, Semigran MJ, et al. Preserved right ventricular ejection fraction predicts exercise capacity and survival in advanced heart failure. J Am Coll Cardiol 1995;25:1143-53.

3. Ghio S, Gavazzi A, Campana C, et al. Independent and additive prognostic value of right ventricular systolic function and pulmonary artery pressure in patients with chronic heart failure. J Am Coll Cardiol 2001;37:183-8.

4. Kjaergaard J, Akkan D, Iversen KK, et al. Right ventricular dysfunction as an independent predictor of short- and long-term mortality in patients with heart failure. Eur J Heart Fail 2007;9:610-16.

5. D'Alonzo GE, Barst RJ, Ayres SM, et al. Survival in patients with primary pulmonary hypertension. Results from a national prospective registry. Ann Intern Med 1991;115:343-9.

6. Kanemoto $\mathrm{N}$. Natural history of pulmonary hemodynamics in primary pulmonary hypertension. Am Heart J 1987;114:407-13.

7. Sandoval J, Bauerle O, Palomar A, et al. Survival in primary pulmonary hypertension. Validation of a prognostic equation. Circulation 1994;89:1733-44.

8. Kawut SM, Horn EM, Berekashvili KK, et al. New predictors of outcome in idiopathic pulmonary arterial hypertension. Am J Cardiol 2005;95:199-203.

9. Chaparro C, Scavuzzo M, Winton T, et al. Status of lung transplant recipients surviving beyond five years. $J$ Heart Lung Transplant 1997;16:511-16.

10. Charman SC, Sharples LD, McNeil KD, et al. Assessment of survival benefit after lung transplantation by patient diagnosis. $J$ Heart Lung Transplant 2002;21:226-32.

11. Egan TM, Bennett LE, Garrity ER, et al. Predictors of death on the UNOS lung transplant waiting list: results of a multivariate analysis. $J$ Heart Lung Transplant 2001;20:242.
12. Smits JM, Vanhaecke J, Haverich A, et al. Waiting for a thoracic transplant in Eurotransplant. Transpl Int 2006;19:54-66.

13. De Meester J, Smits JM, Persijn GG, et al. Lung transplant waiting list: differential outcome of type of end-stage lung disease, one year after registration. $J$ Heart Lung Transplant 1999;18:563-71.

14. Haddad F, Doyle R, Murphy DJ, et al. Right ventricular function in cardiovascular disease, part II: pathophysiology, clinical importance, and management of right ventricular failure. Circulation 2008;117:1717-31.

15. Maddahi J, Berman DS, Matsuoka DT, et al. A new technique for assessing right ventricular ejection fraction using rapid multiple-gated equilibrium cardiac blood pool scintigraphy. Description, validation and findings in chronic coronary artery disease. Circulation 1979:60:581-9.

16. Konstam MA, Kahn PC, Curran BH, et al. Equilibrium (gated) radionuclide ejection fraction measurement in the pressure or volume overloaded right ventricle. Comparison of three methods. Chest 1984;86:681-7.

17. Xue QF, MacNee W, Flenley DC, et al. Can right ventricular performance be assessed by equilibrium radionuclide ventriculography? Thorax 1983;38:486-93.

18. Standardization of Spirometry, 1994 Update. American Thoracic Society. Am J Respir Crit Care Med 1995;152:1107-36.

19. Matthay RA, Arroliga AC, Wiedemann HP, et al. Right ventricular function at rest and during exercise in chronic obstructive pulmonary disease. Chest 1992;101(5 Suppl 5):255S-62S.

20. Matthay RA, Berger HJ, Davies RA, et al. Right and left ventricular exercise performance in chronic obstructive pulmonary disease: radionuclide assessment. Ann Intern Med 1980;93:234-9.

21. Oliver RM, Fleming JS, Dawkins KD, et al. Right ventricular function at rest and during submaximal exercise assessed by $81 \mathrm{Krm}$ equilibrium ventriculography in normal subjects. NuCl Med Commun 1993:14:36-40.

22. Oliver RM, Fleming JS, Waller DG. Right ventricular function at rest and during exercise in chronic obstructive pulmonary disease. Comparison of two radionuclide techniques. Chest 1993;103:74-80.

23. Matthay RA, Berger HJ, Davies RA, et al. Effect of steady state exercise on right and left ventricular performance in chronic obstructive pulmonary disease. Noninvasive assessment by radionuclide angiocardiography. Chest 1980;77(Suppl 2):303.

24. Morrison DA. Pulmonary hypertension in chronic obstructive pulmonary disease: the right ventricular hypothesis. Chest 1987:92:387-9.

25. Jezek V, Schrijen F, Sadoul P. Right ventricular function and pulmonary hemodynamics during exercise in patients with chronic obstructive bronchopulmonary disease. Cardiology 1973;58:20-31.

26. Mahler DA, Brent BN, Loke J, et al. Right ventricular performance and central circulatory hemodynamics during upright exercise in patients with chronic obstructive pulmonary disease. Am Rev Respir Dis 1984:130:722-9.

27. Tomanek RJ. Response of the coronary vasculature to myocardial hypertrophy. J Am Coll Cardiol 1990;15:528-33.

28. Chin KM, Kim NH, Rubin LJ. The right ventricle in pulmonary hypertension. Coron Artery Dis 2005;16:13-18.

29. van Wolferen SA, Marcus JT, Westerhof N, et al. Right coronary artery flow impairment in patients with pulmonary hypertension. Eur Heart J 2008;29:120-7.

30. Gomez A, Bialostozky D, Zajarias A, et al. Right ventricular ischemia in patients with primary pulmonary hypertension. J Am Coll Cardiol 2001;38:1137-42.

31. Olvey SK, Reduto LA, Stevens PM, et al. First pass radionuclide assessment of right and left ventricular ejection fraction in chronic pulmonary disease. Effect of oxygen upon exercise response. Chest 1980;78:4-9.

32. Kawut SM, O'Shea MK, Bartels MN, et al. Exercise testing determines survival in patients with diffuse parenchymal lung disease evaluated for lung transplantation. Respir Med 2005;99:1431-9.

33. King TE Jr., Tooze JA, Schwarz MI, et al. Predicting survival in idiopathic pulmonary fibrosis: scoring system and survival model. Am J Respir Crit Care Med 2001;164:1171-81.

34. McCann GP, Gan CT, Beek AM, et al. Extent of MRI delayed enhancement of myocardial mass is related to right ventricular dysfunction in pulmonary artery hypertension. AJR Am J Roentgenol 2007;188:349-55. 